\title{
Bronchiolitis Obliterans Organizing Pneumonia Mimicking Community-Acquired Pneumonia
}

\author{
Em Ward, MD, and Jobn Rog, $M D$
}

Background: Bronchiolitis obliterans organizing pneumonia is a rare disease that mimics infectious pneumonia. Most patients respond well to corticosteroid therapy.

Methods: We report a single case and findings from an English language literature search of MEDLINE using key words "bronchiolitis obliterans organizing pneumonia."

Results and Conclusions: Bronchiolitis obliterans organizing pneumonia should be considered when a patient with pneumonia does not respond to antibiotics and has multiple patchy infiltrates and characteristic bronchoalveolar lavage patterns. A tissue sample is required for definitive diagnosis. Infection by a multiresistant organism can occur with multiple antibiotic therapy and concomitant use of corticosteroids, particularly when no initial infecting organism is identified. (J Am Board Fam Pract 1998;11:41-5.)

Bronchiolitis obliterans organizing pneumonia is a rare clinical entity that family physicians should consider when a patient does not respond to usual treatment of infectious pneumonia. Clinical symptoms and signs of bronchiolitis obliterans organizing pneumonia mimic infectious pneumonia, but therapy for this condition is corticosteroids, not antibiotics. Bronchoalveolar lavage or open-lung biopsy might be required for definitive diagnosis. Most patients respond well to treatment, but a subset of patients, less than 10 percent of all patients, will die of this illness. We describe a case of ostensibly progressive disease that could have been complicated by superinfection. We want physicians to be wary of the combination of prolonged antibiotic use and high-dose corticosteroids.

\section{Methods}

We report a single case of bronchiolitis obliterans organizing pneumonia and findings from an English language literature search of MEDLINE using key words "bronchiolitis obliterans organizing pneumonia."

\section{Illustrative Case}

A 55-year-old man complained to his family physician of a 3-week history of exhaustion, dysp-

Submitted, revised, 7 May 1997.

From the Department of Family Practice, Michigan State University Kalamazoo - Center for Medical Studies, Kalamazoo. Address reprint requests to John Rog, MD, MSUKCMS, 1000 Oakland Dr, Kalamazoo, MI 49008. nea, fever and chills, and 15- to 20-pound weight loss. He was a long-term heavy smoker ( 40 to 80 pack years) and a frequent traveler. Recent travel was limited to metropolitan areas in the United States. His chest radiograph showed emphysematous changes and a possible early right lower lobe infiltrate. Clarithromycin was prescribed $(500 \mathrm{mg}$ twice a day for 10 days), but he had no clinical response and sought care again 1 week later. During this time he developed a small amount of hemoptysis. He was given an injection of ceftriaxone and prescribed cephalexin. A truncal rash appeared after cephalosporin administration, and he again returned. His antibiotic was changed to ofloxacin ( $400 \mathrm{mg}$ twice a day). After only 1 day of ofloxacin therapy, he returned to his physician's office. A repeated chest radiograph showed a patchy alveolar right lower lobe infiltrate and small left lower lobe infiltrate. He was admitted to the hospital for further evaluation and treatment.

When admitted to the hospital, the patient weighed 145 pounds, his temperature was $97.6^{\circ} \mathrm{F}$, pulse 72 beats per minute, respirations $18 / \mathrm{min}$, and blood pressure $132 / 76 \mathrm{mmHg}$. He was cachectic and had decreased breath sounds and dullness at the right lung base. He also had pedal edema (2+) and pretibial edema (1+) bilaterally. Oxygen saturation on room air was 60 percent. His arterial blood gas readings on $6 \mathrm{~L}$ of oxygen per minute by nasal cannula were $\mathrm{pH} 7.41, \mathrm{pO}_{2} 61$ $\mathrm{mmHg}, \mathrm{pCO}_{2} 78 \mathrm{mmHg}$, oxygen saturation 93 percent, and bicarbonate $38.2 \mathrm{mEq} / \mathrm{L}$. 
On day 3 he developed rales on chest auscultation, which persisted throughout his hospitalization. Extensive laboratory studies showed pancytopenia, hypoalbuminemia, and hypocalcemia. He was given intravenous clindamycin (600 $\mathrm{mg}$ three times a day) and gentamicin $(320 \mathrm{mg} / \mathrm{d})$, but his fever persisted. Clarithromycin (500 $\mathrm{mg}$ twice a day) was added on day 3 . His peripheral edema resolved, and subjectively he improved slightly after supplemental oxygen. Sputum and blood cultures were repeated many times and were negative. Findings from an echocardiogram to rule out right heart failure and endocarditis and a vascular Doppler study of the lower extremities to exclude deep venous thrombosis were noncontributory.

A Westergren erythrocyte sedimentation rate was $117 \mathrm{~mm} / \mathrm{h}$ and an alpha $\mathrm{l}_{1}$-antitrypsin level was $435 \mathrm{mg} / \mathrm{dL}$ (roughly two times the upper limit of normal). Rheumatoid factor and antinuclear antibody titers were negative; a Mycoplasma immunoglobulin G (IgG) level was positive at $0.35 \mathrm{mg} / \mathrm{dL}$. Bilateral infiltrates seen on chest radiographs persisted without improvement and developed an interstitial pattern.

A noninfectious cause was suspected. The differential diagnoses included bronchiolitis obliterans organizing pneumonia, vasculitis, and lymphoma. The result of a bone marrow biopsy to evaluate the pancytopenia and to assess for an infiltrative process was nondiagnostic dysplasia.

At an open-lung biopsy there was boggy edematous parenchyma with bullous and panacinar emphysema. Special stains and cultures were negative for all organisms except methicillin-resistant Staphylococcus aureus (MRSA) in the broth. A Legionella titer (whether IgG or IgM was unknown) was less than 1:128 with a total antibody level of $5.4 \mathrm{mg} / \mathrm{dL}$. Histologic sections showed a noninfectious organizing pneumonia with vasculitis limited to the affected area.

Postoperatively, the patient was given highdose intravenous methylprednisolone, but he had no clinical response. An antinuclear cytoplasmic antibody level was negative. The patient's clinical course deteriorated; he had persistent oxygen desaturation with exertion and progressive weakness, and he did not eat. Tube feedings were initiated. Impending respiratory failure led to intubation and mechanical ventilation. A Swan-Ganz catheter was placed. The patient developed multiple organ-system failure with rapid rises in renal and hepatic indices. He had completed 7 days of clindamycin therapy, 14 days of gentamicin therapy, and 14 days of clarithromycin therapy, and he was off antibiotics for 2 days when a urine culture came back positive for MRSA. The patient was then given vancomycin ( $1 \mathrm{~g}$ every 12 hours), ciprofloxacin (400 mg every 12 hours), and clindamycin (600 mg every 8 hours). The patient died 2 days later, and an autopsy was denied by the family. Two blood cultures became positive for MRSA postmortem.

\section{Bronchiolitis Obliterans Organizing Pneumonia}

Bronchiolitis obliterans organizing pneumonia is a syndrome with distinct clinical, radiographic, functional, and histologic features. It is also referred to as a cryptogenic organizing pneumonia when the cause is considered idiopathic. Frequently it is after antibiotic therapy fails to have an effect on what is believed to be infectious pneumonitis that the diagnosis is considered.

\section{Epidemiology}

No sex predilection exists for bronchiolitis obliterans organizing pneumonia. ${ }^{1-10}$ This disease is found in adults whose average age falls within the sixth decade of life. ${ }^{1-11}$ Two to four cases are estimated to occur each year at large medical centers. ${ }^{11,12}$ One report of a projected cumulative prevalence was 12 per 100,000 admissions at a major teaching medical center. ${ }^{10}$

\section{Cause and Etiologic Associations}

Although two thirds of cases are considered idiopathic, bronchiolitis obliterans organizing pneumonia has been associated with connective tissue disorders, organ transplants, toxic fume inhalation, $\subseteq$ and drug toxicity. ${ }^{1-29}$ Infections with viruses, in- $N$ cluding the human immunodeficiency virus (HIV), and atypical organisms have also been reported precursors. 2,4,6,9,10,19,21,27,29

\section{Clinical Findings}

More than 70 percent of patients report cough, $\stackrel{\oplus}{\rightarrow}$ dyspnea, and weight loss. 1,3,5-7,9,10,12,30,31 Most patients have a prodromal flu-like illness with fever and chills. Duration of symptoms can range from weeks to months. ${ }^{1,3,5-10,12,30,31}$ Approximately 70 व to 80 percent of patients have rales on auscultation. $1,3,5,6,8,9,12,30$ 
There is no diagnostic laboratory test. The erythrocyte sedimentation rate is frequently elevated, often exceeding $100 \mathrm{~mm} / \mathrm{h}$. and blood cultures are generally negative. Radiographically, 70 to 100 percent of patients have patchy alveolar infiltrates in one or more lobes. Ten to 20 percent have interstitial infiltrates, and less than 10 percent have a mixed-pattern of pulmonary infiltrates. $1,3,5-12$ A propensity for a peripheral location of the infiltrates appears on computed tomographic scanning, ${ }^{6,11}$ and these patchy infiltrates can be migratory, $7,8,10,12$

Pulmonary function testing shows a restrictive pattern with decreased diffusion capacity and hypoxemia. ${ }^{1,3,5-10,12,30,31}$ Smokers can also have an obstructive component, ${ }^{4,5}$ With bronchoalveolar lavage a mixed and colorful cellularity is usually noted, as are increases in neutrophils, eosinophils, and particularly lymphocytes. ${ }^{3,5,7,8} \mathrm{~A}$ consistent finding on bronchoalveolar lavage is a decreased CD4-CD8 ratio. ${ }^{6-8}$

\section{Histology}

Diagnostic findings of bronchiolitis obliterans organizing pneumonia include plugs of granulation tissue within the lumens of distal bronchioles, extending into alveolar ducts and alveoli. - $^{1-3,5-10,12,30-32}$ There can be an interstitial mononuclear cell infiltrate,, 212 and alveolar accumulation of macrophage foam cells is common. Generally, the parenchymal architecture is preserved without honeycombing, ${ }^{1-3,5-10,12,30-32}$ although honeycombing can appear incidentally with end-stage disease. ${ }^{9,12,32}$ There is the opinion, however, that honeycombing suggests the diagnosis is not bronchiolitis obliterans organizing pneumonia. ${ }^{32}$

\section{Treatment}

High-dose corticosteroid therapy usually results in dramatic improvement, often with complete resolution of clinical and radiologic findings. $1,4-8,10,30$ Patients improve clinically within days to weeks. Pulmonary function testing and radiologic findings usually normalize within months. ${ }^{6,10}$ Bronchoalveolar lavage cell findings appear to change slowly, requiring months to years to revert to normal. 6 Prednisone or prednisolone prescribed in dosages of 1 to $1.5 \mathrm{mg} / \mathrm{kg} / \mathrm{d}$ for 1 to 3 months is a standard practice. ${ }^{1,4-7}$ Intravenous methylprednisolone may be given as initial therapy for 3 to 5 days at 1 to $3 \mathrm{~g} / \mathrm{d}$ in divided doses. 5.9 Early taper- ing of treatment frequently results in relapse. Some cases have required treatment for longer than 1 year. ${ }^{1,4,10}$

In progressive, refractory cases, cytotoxic agents, such as cyclophosphamide and azathioprine, have been tried without success.,9 Two cases of resolution have been reported after treatment with erythromycin in one case and erythromycin and tetracycline in the other; however, the author of the report considered these resolutions to be spontaneous, as no infectious agent was identified in either case. ${ }^{1}$

\section{Outcome}

Generally, 60 to 70 percent of patients have complete resolution after corticosteroid treatment. ${ }^{1-12}$ Twenty to 30 percent improve with some residual deficits either on pulmonary function testing or in radiographic findings. ${ }^{10}$ An estimated less than 10 percent of patients succumb to progressive disease. ${ }^{1-5,7,8,10}$ In a 1995 review of 296 cases worldwide, ${ }^{10}$ Alasaly et al report 65 percent, 27 percent, and 8 percent, respectively, for the above outcomes.

\section{Discussion}

The clinicopathologic syndrome now referred to as bronchiolitis obliterans organizing pneumonia might have been described as early as $1901 .^{1}$ In $1985 \mathrm{Epler}^{1}$ was the first to categorize the clinical and histologic findings into a single entity. Although the general theme is constant, variations have led to some difficulty in interpreting what should actually be considered bronchiolitis obliterans organizing pneumonia, particularly with regard to whether the histologic findings are associated with any kind of exposure or infection. The term cryptogenic organizing pneumonia is preferred by some authors but should be applied only if the disease is considered to be idiopathic. 10,30,31,33-35

Authors disagree about whether bronchiolitis obliterans organizing pneumonia belongs in the spectrum of interstitial diseases. ${ }^{9,32}$ Recent evidence indicates that interstitial scarring and honeycombing can occur with atypical, progressive disease. ${ }^{9}$ Differential diagnoses include usual interstitial pneumonitis, chronic eosinophilic pneumonia, infectious pneumonitis, local organizing pneumonia, diffuse alveolar damage, hypersensitivity pneumonitis, Wegener's granulomatosis, and lymphoproliferative disorders. The diagnostic differ- 
Table 1. Prognostic Features of Bronchiolitis Obliterans Organizing Pneumonia.

\begin{tabular}{lll}
\hline Feature & Good Prognosis & Bad Prognosis \\
\hline History & $\begin{array}{l}\text { Mild dyspnea } \\
\text { Idiopathic }\end{array}$ & $\begin{array}{l}\text { Severe dyspnea } \\
\text { Associated } \\
\text { connective tissue } \\
\text { disorder } \\
\text { ?Smoking } \\
\text { Bilateral interstitial } \\
\text { infiltrates }\end{array}$ \\
Radiology & $\begin{array}{l}\text { Patchy infiltrates } \\
\text { Multiple lobes } \\
\text { lavage }\end{array}$ & Mixed cellularity \\
cack of lympho- \\
\hline
\end{tabular}

ences between these entities have been outlined elsewhere. $2,5,6,8,31,32,34,36$

When we reviewed the reported cases, we found that a relatively consistent pattern of history and radiologic and bronchoalveolar lavage cell findings indicates prognosis. If dyspnea is mild and the cause is considered idiopathic, the prognosis is good, with the patient experiencing either spontaneous resolution or prompt response to corticosteroid treatment. Severe dyspnea and a more prolonged or rapidly progressive course are associated with a poor prognosis. Concomitant connective tissue disorder is also associated with a poor prognosis. Patchy infiltrates in multiple lobes seen on chest radiographs or CT scans are associated with good prognosis, whereas bilateral interstitial infiltrates are associated with poor prognosis. Findings of mixed cellularity on bronchoalveolar lavage are associated with good prognosis, whereas a lack of lymphocytosis on bronchoalveolar lavage portends a poor prognosis (Table 1). 1,3,5,9,12

The patient described here had a clinical course similar to that of a group of patients who had rapidly progressive disease reported by Cohen et al. ${ }^{9}$ Our patient's underlying emphysema and generally weakened state might have contributed to his poor response. The prolonged use of multiple antibiotics (outpatient and inpatient) could have contributed to the development of a multiresistant organism that was able to disseminate in the presence of high-dose corticosteroids. The MRSA in our patient might have been the multiresistant organism that first appeared in the broth and then caused overwhelming sepsis.

\section{Conclusion}

Bronchiolitis obliterans organizing pneumonia is a rare syndrome characterized by cough, dyspnea, weight loss, fever, and rales. Most patients respond well to corticosteroid therapy. A subset of patients with severe dyspnea, prolonged course, and bilateral interstitial infiltrates seen on chest radiograph tend to have poor prognosis. Lack of lymphocytosis on bronchoalveolar lavage is also an important finding in predicting poor response to therapy. Bronchiolitis obliterans organizing pneumonia should be considered when a presumptive diagnosis of community-acquired pneumonia does not respond to appropriate treatment.

If a patient has multiple patchy infiltrates, characteristic bronchoalveolar lavage patterns, and no response to antibiotics, it would be appropriate to consider proceeding to corticosteroid therapy without open-lung biopsy. A tissue sample is required for definitive diagnosis, however. The clinician must be wary of infection by a multiresistant organism as a consequence of multiple antibiotic therapy with concomitant use of corticosteroids, particularly when no initial infecting organism is identified.

\section{Acknowledgments}

Kevin Beckman, MD, and William Leeburg, MD, provided a pathology review for this report.

\section{References}

1. Epler GR, Colby TV, McLoud TC, Carrington CB, Gaensler EA. Bronchiolitis obliterans organizing pneumonia. N Engl J Med 1985;312:152-8.

2. Chandler PW, Shin MS, Friedman SE, Myers JL, Katzenstein AL. Radiographic manifestations of bronchiolitis obliterans with organizing pneumonia vs usual interstitial pneumonia. AJR Am J Roentgenol 1986;147:899-906.

3. Cordier JF, Loire R, Brune J. Idiopathic bronchiolitis obliterans organizing pneumonia. Definition of characteristic clinical profiles in a series of $16 \mathrm{pa}$ tients. Chest 1989;96:999-1004.

4. Epler GR. Bronchiolitis obliterans organizing pneumonia: definition and clinical features. Chest 1992; 102 (1 Suppl):2S-6S.

5. King TE Jr, Mortenson RL. Cryptogenic organizing pneumonitis: The North American experience. Chest 1992;102(1 Suppl):8S-13S.

6. Costabel U, Teschler H, Schoenfeld B, Hartung W, Nusch A, Guzman J, et al. BOOP in Europe. Chest 1992;102(1 Suppl):14S-20S.

7. Yamamoto $M$, Ina $Y$, Kitaichi $M$, Harasawa $M$, Tamura M. Clinical features of BOOP in Japan. Chest 1992;102(1 Suppl):21S-5S.

8. Nagai $S$, Aung $H$, Tanaka $S$, Satake $N$, Mio T, Kawatani A, et al. Bronchoalveolar lavage cell findings in patients with BOOP and related diseases. 
Chest 1992;102(1 Suppl):32S-7S.

9. Cohen AJ, King TE Jr, Downey GP. Rapidly progressive bronchiolitis obliterans with organizing pneumonia. Am J Respir Crit Care Med 1994;149: $1670-5$.

10. Alasaly K, Muller N, Ostrow DN, Champion P, FitzGerald JM. Cryptogenic organizing pneumonia. A report of 25 cases and a review of the literature. Medicine (Baltimore) 1995;74:201-11.

11. Nishimura K, Itoh H. High-resolution computed tomographic features of bronchiolitis obliterans organizing pneumonia. Chest 1992;102(1 Suppl):26S-31S.

12. Costabel U, Guzman J, Teschler H. Bronchiolitis obliterans with organising pneumonia: outcome. Thorax 1995;50(Suppl 1):S59-S64.

13. Schwarz MI, Matthay RA, Sahn SA, Stanford RE, Marmorstein BL, Scheinhorn DJ. Interstitial lung disease in polymyositis and dermatomyositis: analysis of six cases and review of the literature. Medicine (Baltimore) 1976;55:89-104.

14. Yousem SA, Colby TV, Carrington CB. Lung biopsy in rheumatoid arthritis. Am Rev Respir Dis 1985; 131:770-7.

15. Tazelaar HD, Viggiano RW, Pickersgill J, Colby TV. Interstitial lung disease in polymyositis and dermatomyositis. Clinical features and prognosis as correlated with histologic findings. Am Rev Respir Dis 1990;141:727-33.

16. Matteson EL, Ike RW. Bronchiolitis obliterans organizing pneumonia and Sjögren's syndrome. J Rheumatol 1990;17:676-9.

17. Patel RC, Dutta D, Schonfeld SA. Free-base cocaine use associated with bronchiolitis obliterans organizing pneumonia. Ann Intern Med 1987;107:186-7.

18. Camus P, Lombard JN, Perrichon M, Piard F, Guerin JC, Thivolet FB, et al. Bronchiolitis obliterans organizing pneumonia in patients taking acebutolol or amiodarone. Thorax 1989;44:711-5.

19. Santrach PJ, Askin FB, Wells RJ, Azizkhan RG, Merten DF. Nodular form of bleomycin-related pulmonary injury in patients with osteogenic sarcoma. Cancer 1989;64:806-11.

20. Allen JN, Wewers MD. HIV-associated bronchiolitis obliterans organizing pneumonia. Chest 1989; 96:197-8.

21. Kuwano K, Hayashi S, MacKenzie A, Hogg JC. Detection of adenovirus DNA in paraffin-embedded lung tissues from patients with bronchiolitis obliterans and organizing pneumonia (BOOP) using in situ hybridization. Am Rev Respir Dis 1990;141:A319.

22. Sepuya SM, Grzybowski S, Burton JD, Clement JG. Diffuse lung changes associated with gold therapy. Can Med Assoc J 1978;118:816-8.

23. Heyd J, Simmeran A. Gold-induced lung diseases. Postgrad Med J 1983;59:368-70.

24. Morley TF, Komansky HJ, Adelizzi RA, Giudice JC. Pulmonary gold toxicity. Eur J Respir Dis 1984;65: 627-32.

25. Dreis DF, Winterbauer FH, Van Norman GA, Sullivan SL, Hammar SP. Cephalosporin-induced interstitial pneumonitis. Chest 1984;86:138-40.

26. Takimoto CH, Lynch D, Stulbarg MS. Pulmonary infiltrates associated with sulindac therapy. Chest 1990;97:230-2.

27. Camp M, Mehta JB, Whitson M. Bronchiolitis obliterans and Nocardia asteroides infection of the lung. Chest 1987;92:1107-8.

28. McCormick J, Cole S, Lahirir B, Knauft F, Cohen S, Yoshida T. Pneumonitis caused by gold salt therapy: evidence for the role of cell-mediated immunity in its pathogenesis. Am Rev Respir Dis 1980;122:145-52.

29. Peramaki E, Salmi I, Kava T, Romppanen T, Hakkarainen $T$. Unilateral bronchiolitis obliterans organizing pneumonia and bronchoalveolar lavage neutrophilia in a patient with parainfluenza 3 virus infection. Respir Med 1991;85:159-61.

30. Corrin B. Bronchiolitis obliterans organizing pneumonia. A British view. Chest 1992;102(1 Suppl):7S.

31. Lynch JP 3d, Sitrin RG. Noninfectious mimics of community-acquired pneumonia. Semin Respir Infect 1993;8:14-45.

32. Colby TV. Pathologic aspects of bronchiolitis obliterans organizing pneumonia. Chest 1992;102(1 Suppl):38S-43S.

33. Izumi $T$. Introduction (International Congress on BOOP). Chest 1992;102(1 Suppl):1S.

34. Izumi T. Congress summary (International Congress on BOOP). Chest 1992;102(1 Suppl):50S.

35. Ezri T, Kunichezky S, Eliraz A, Soroker D, Halperin D, Schattner A. Bronchiolitis obliterans-current concepts. QJ Med 1994;87:1-10.

36. Kitaichi $M$. Differential diagnosis of bronchiolitis obliterans organizing pneumonia. Chest 1992;102(1 Suppl):44S-9S. 